\title{
Online Interstate Student Diplomats Discuss What Justifies War: "We Don't Want People to Die, but We Don't Want to Lose Our Oil."
}

\author{
Joe O'Brien ${ }^{1}$, Brian Bechard ${ }^{2}$, Thomas Fulbright ${ }^{3}$, Kori Green ${ }^{4} \&$ Nick Lawrence ${ }^{5}$ \\ ${ }^{1}$ Department of Curriculum \& Teaching, University of Kansas, Lawrence, Kansas, USA \\ ${ }^{2}$ Pioneer Ridge Middle School, Gardner, Kansas, USA \\ ${ }^{3}$ Hope Street Academy, Topeka, Kansas, USA \\ ${ }^{4}$ El Dorado Middle School, El Dorado, Kansas, USA \\ ${ }^{5}$ East Bronx Academy, New York, USA \\ Correspondence: Joe O'Brien, Department of Curriculum \& Teaching, University of Kansas, 1122 West Campus \\ Road, Lawrence, KS, 66045, USA. Tel: 1-785-864-9663. E-mail: jeobrien@ku.edu
}

Received: April 6, 2012 Accepted: May 4, $2012 \quad$ Published: June 1, 2012

doi:10.5539/jel.v1n1p99 URL: http://dx.doi.org/10.5539/jel.v1n1p99

\begin{abstract}
Given that most research in online discussion addresses asynchronous discussions and that middle school students receive little opportunity to engage in sustained, substantive dialogues, there is a need to develop and pilot ways to instructional support students in sustained, online synchronous discussions about public policy issues such as why nations go to war. This article presents: a blended learning instructional model for an online synchronous discussion that was developed and piloted; instructional and logistical issues raised with the model; suggestions on conducting interschool online discussions to promote students' online voice; and, samples of students' thinking about what justifies war.
\end{abstract}

Keywords: online, synchronous, discussion

\section{Introduction}

If "participatory media education and civic education are inextricable" (Rheingold, 2008, p. 103), then learning to use digital social media is critical for students as they learn "to make informed and reasoned decisions for the public good as citizens of a culturally diverse, democratic society in an interdependent world" (National Council for the Social Studies, 1994). Few public policy decisions are more importantthan those regarding the nation's use of military forces. What better way to further students' ability to engage in public, democratic discussions than by involving them in a continuous, sequenced online synchronous discussion about what justifies war? In so doing, we involved over 300 students from four schools in a year-long discussion where they used Ning to draft a list of reasons that might justify a nation going to war, applied this list to five separate hypothetical situations grounded in U.S. historical events, and synthesized their thinking to create a "final" list that they then applied to events unfolding during the "Arab spring" In this article we describe the results of a pilot study where we addressed several research questions related to the development, instructional, and logistical use of a blended learning model for online synchronous discussion (OSD) among middle school students in four schools. In so doing, we provide: a theoretical context for the pilot study; a description of those involved; an explanation and discussion of the model that we developed and piloted; pedagogical, managerial \& technical support issues raised with the model; suggestions on conducting interschool online discussions to promote students' online voice; samples of students' thinking about what justifies war to support the discussion of the model; and lessons learned about the pedagogical support needed for our blended learning approach.

\section{Relevant Scholarship and Research Questions}

\subsection{Establishing a Theoretical Context}

Since seventy three percent of online teens usesocial networking sites (SNS) (Lemhart, Ling, Campbell, \& Purcell, 2010), the "informal learning that occurs in the context of participatory media" offers "significant 
opportunities for increased student engagement in formal learning settings" so long as teachers connect students' "experience with communication technologies" to sound "pedagogy...content...[and] learning objectives" (Bull et al., 2008, p. 6). While teachers need to foster students' ability to use SNS for academic and civic purposes, as Bull et al. (2008) recognized: "Teachers have limited models for effective integration of media in their teaching" (p. 2).We accepted this as a challenge worthy of undertaking, given how OSD could provide for "a sense of social presence" (Wang, 2005, p. 21) for middle school students and how "online instruction needs to move away from teacher-centered models toward more learner- centered ones in which student collaboration is encouraged" (An, Kim \& Kim, 2008, p. 66). We undertook a pilot study on a model for conducting a year-long sustained and sequenced set of synchronous online discussions among students from four schools about a key public policy question, i.e., what justifies a nation going to war, using a Ning site (www.justwar.ning.com - Refer to Screenshot 1)

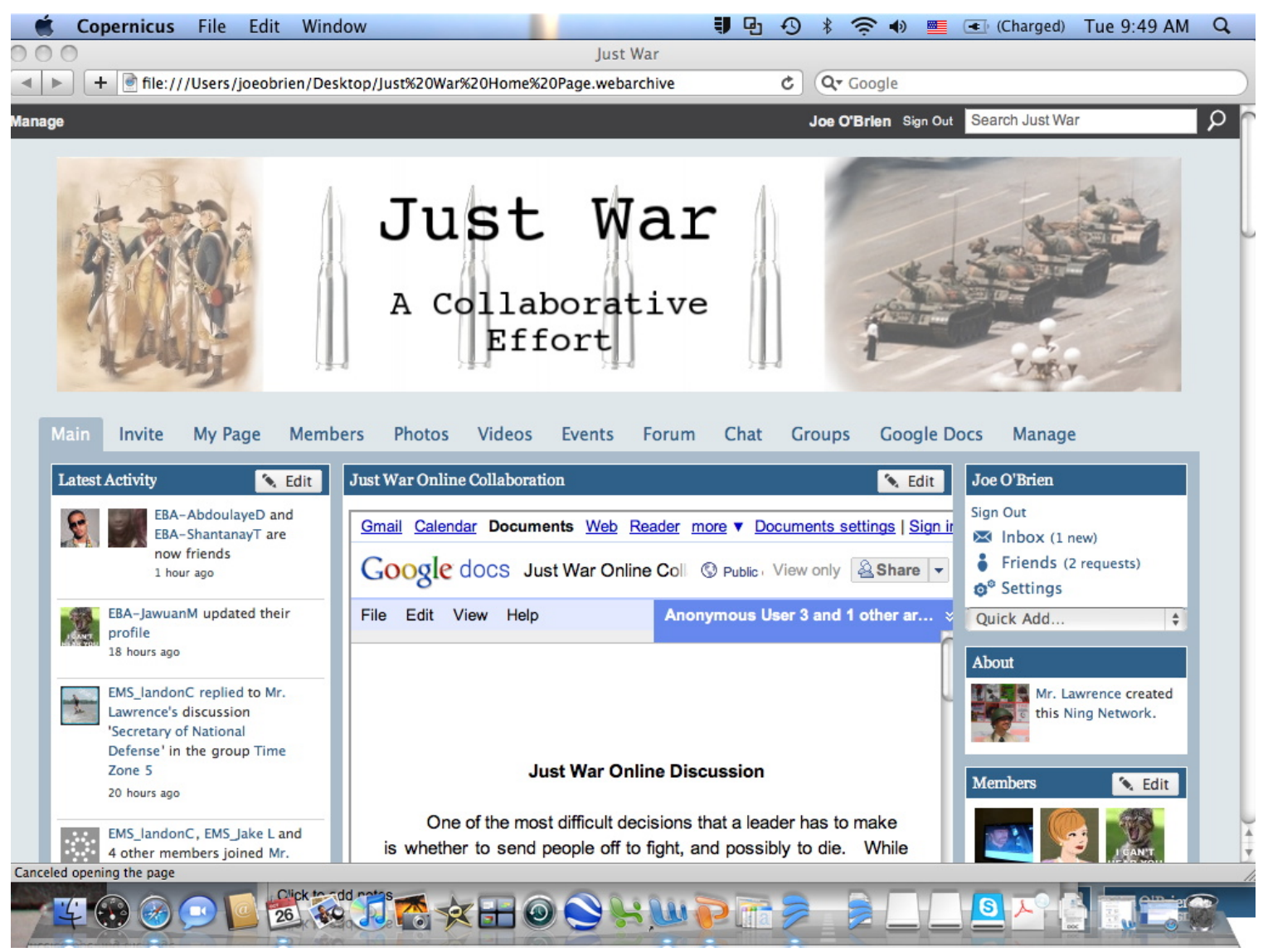

Screenshot 1. Just War Home Page

Synchronous online forums support "real-time, many-to-many textual interactions" during which students "experience 'same-time, any place' collaboration" (Shi, et al., 2008, p. 6), enabling students from different schools to engage "in public dialogue on cutting-edge issues" (Greenhow, Robelia, \& Hughes, 2009, p. 249). Synchronous online "types of collaboration demonstrate the important traits of immediacy, fast planning, problem- solving, scheduling, and decision-making, which can be difficult to replicate in an asynchronous environment" (Ibid). Wu (2005) identified similar characteristics of online synchronous discussion: "With its feature of real time interaction, the OSD can build a sense of social presence and a heightened sense of involvement in the ongoing communication events through quick feed-back on ideas, support consensus and decision making" (p. 304). While the research base for synchronous systems is growing, most research in online discussion "has focused on asynchronous systems" (Shi, et al., p. 4). As a result, "the literature has...little to offer about what constitutes effective online human support of synchronous discussions" (Asterham \& Schwarz, 2010, p. 260), highlighting Bull et al.'s (2008) concern.

Drawing upon the work of Ashton et al (1999), Lund (2004) identified four types of support provided by students 
and teachers during online learning, three of which are relevant here: managerial, technical, and pedagogical. We thought this construct was appropriate not only for the implementation, but also the development, of the model, particularly given the K-12 setting. Managerial issues related toOSDs include "getting students online at the same time" (Branon \& Essex, 2001), such as adapting to the differences in time zones and school schedules, and ensuring students have easy, quick access to the site (Chen, et al, 2005). Technical issues include selecting an online application that is "fit for purpose" (Bowler, 2009) and acceptable to each district. Since students need to receive "intentional instructional support" so as "to develop accurate and integrative knowledge" (Chen \& Bradshaw, 2007, p. 359), the pedagogical support required the planning and testing of face-to-face (f2f) instructional material and of the content for the online discussion, as well as aligning the substance of the discussions with local curricula.

\subsection{Research Questions}

In applying such support issues to the development and implementation of the blended learning instructional model, we sought to address these questions:

1) What characterizes a blended learning model that incorporates f $2 \mathrm{f}$ offline within-class discussions and inter-schools OSDs?

2) What managerial, pedagogical and technical support issues are raised by the development and implementation of a blended learning model for OSDs?

\section{Methods}

\subsection{Pilot Study Participants and Settings}

Four of us are classroom teachers and one a university professor. Each teacher had about three years of experience. Collectively we represented a diversity of schools and districts: a middle school in a Midwestern rural district; a middle school in a Midwestern small town; a secondary charter school in a Midwestern smaller urban district; and, a middle school in a large Eastern school district. While all four teachers had experience integrating technology into their instruction, only one had had minimal experience with the use of social networking sites and OSD. The student population in the four schools varied greatly, running the gamut from a largely white, homogeneous group in the rural district to economically and ethnically diverse population in the eastern school. The students in theMidwestern urban district attended a charter school, intended for those struggling in the district's traditional schools. Throughout the 2010-2011 school year over 300 students participated in online discussions.

\subsection{Means to Validate the Model}

We used several means to validate the model and corresponding instructional material, as well as to identify and address the pedagogical, managerial, and technical issues raised while implementing the model. First, we used a peer review approach to validate the material used with students. One of us assumed responsibility for the model's design and the content-related instructional material, a second one designed the graphic organizers used for each discussion, and a third one designed the visual aids. We reviewed each other's work prior to each online discussion and revised it accordingly. After each discussion an electronic debriefing occurred where the materials again were reviewed and revised. During this review process we also analyzed the digital transcript of the students' online discussion and the completed graphic organizers that students had uploaded to the site. Second, an observation log was maintained throughout the year where we kept track of concerns and issues to address upon completion of the pilot study. Third, at the end of the academic year we held a face-to-face (f2f) meeting to discuss the appropriateness of the model and the corresponding instructional material, and to identify unmet pedagogical, managerial and technical concerns. Finally, the teacher among us with minimal experience with social media had his students complete an informal pre and post study questionnaire.

Our relative lack of experience with using social media in general and OSD in particular, as well as the "difficulty in moderating large-scale conversations" and ensuring adequate "reflection time for students" (Branon \& Essex, 2001, p. 36), both limited us and caused us to focus on seeking to validate the model and to address the concerns raised by conducting inter-school OSDs. Thus, we onlyanalyzed the substance of what the students discussed for instructional, not research, purposes. As a result, the sample of the students' thinking that we present later is intended more to illustrate the model in action than to draw any inferences about the impact of use of OSDs on the students' thinking. What follows is a discussion of what we learned, starting with an explanation of the blended learning instructional model. 


\section{Discussion of Implementation and Results of Pilot Study}

\subsection{A Blended Learning Approach to Discussing What Justifies War}

Our efforts to integrate participatory media were "at best an art and, more often than not, a series of trial-and-error solutions" (Lankes, 2008, p. 103). While still far from an art form, during the year we became more proficient and systematic about our "trial-and-error solutions" from which emerged a blended learninginstructional model, one with online and $\mathrm{f} 2 \mathrm{f}$ interaction that supported and complemented each other (Refer to Figure 1). There was a substantive and procedural component of the model.

Table 1. Instructional model

The model focuses on answering an essential question: What justifies a nation going to war?

\section{Online Collaboration}

Online interaction allows students to apply their ideas to hypothetical situations and to get feedback from their online peers.

\section{Formative Thinking Round}

Drawing on their prior knowledge and perceptions of war, in $\mathrm{f} 2 \mathrm{f}$ and online settings students determine what they believe justifies a nation going to war. Students' responses are summarized and provided to them as a working list. Students use and refine this list during subsequent discussions.

\section{Application Rounds}

During the second and four subsequent rounds of online discussion students apply the list of reasons to hypothetical situations, ones grounded in real historical events: relations with Native Americans; War of 1812; Civil War; Spanish-American War; and, World War I.Students are not informed about the historical basis for each situation until the $\mathrm{f} 2 \mathrm{f}$ debriefing of online discussion.

After each application round the students' thinking again is summarized and provided to them during f2 $\mathrm{f}$ debriefing discussion. During the debriefing discussion students compare their thinking with what actually occurred, and reconsider the list of reasons.

\section{Synthesis \& Summative Thinking Rounds}

Based on the results of those applications, each group crafts a final list of reasons and supports each reason with one or more historical examples. Students apply this list to contemporary events during an online mock U.N. Security Council.

Substantively, students first generated a list of reasons of what might justify a nation going to war, next applied their reasoning to five hypothetical situations based in historical events, and then reviewed, finalized and applied their list of reasons to events occurring in the Middle East during the "Arab spring." Procedurally, students followed three steps. First, students in f2f large class settings and in small group work in their teachers' classroom prepared for the online discussion, posting the results of their work on the JustWarNing site. Second, students in two to four schools, whose class times overlapped, participated in a series of 30-minute online discussions about what justifies war. Third, after each online discussion students debriefed the discussion through f2f large class and small group work. What proved challenging was addressing the managerial, pedagogical and technical support issues that emerged.

\section{Offline, Face-2-Face(f2f) Collaboration}

The offline, f2f interaction enables students to review their reasoning and reflect on the summaries produced by the professor. Teachers use the face-to-face time to tie the hypothetical situations more substantially into their own curriculum, thereby making the online discussion even more relevant to their students. 


\subsection{Coordinating Synchronous, Interschool Discussions to Cultivate Students' Online Voice}

So as to minimize technical support issues, we chose Ning.com as our platform for several reasons: low cost, accessible to all four schools; easy to navigate chat function; the discussion forums are user-friendly; files are easy to upload; and, the ability to customize a personal home page and "friend" other people on the secure Ning network. The last feature caused some students to refer to the site as "Historybook", a direct reference to Facebook. Moving forward with this aspect of the work, a "like" button function will be added next year, which is one of the main functions used to interact on Facebook. This may actually help the teachers to identify the most popular answers and ideas posted and read by students.

We addressed managerial support issues in several ways. First, in preparation for the first online discussion, each teacher created a home page for all of her/his (f2f) students, which served as an online breakout room for those students (Refer to Screenshot 2). Students used their class home page to familiarize themselves with the Just War Ning before the first synchronous online discussion, to conduct classroom follow-up work, and to practice using the site.

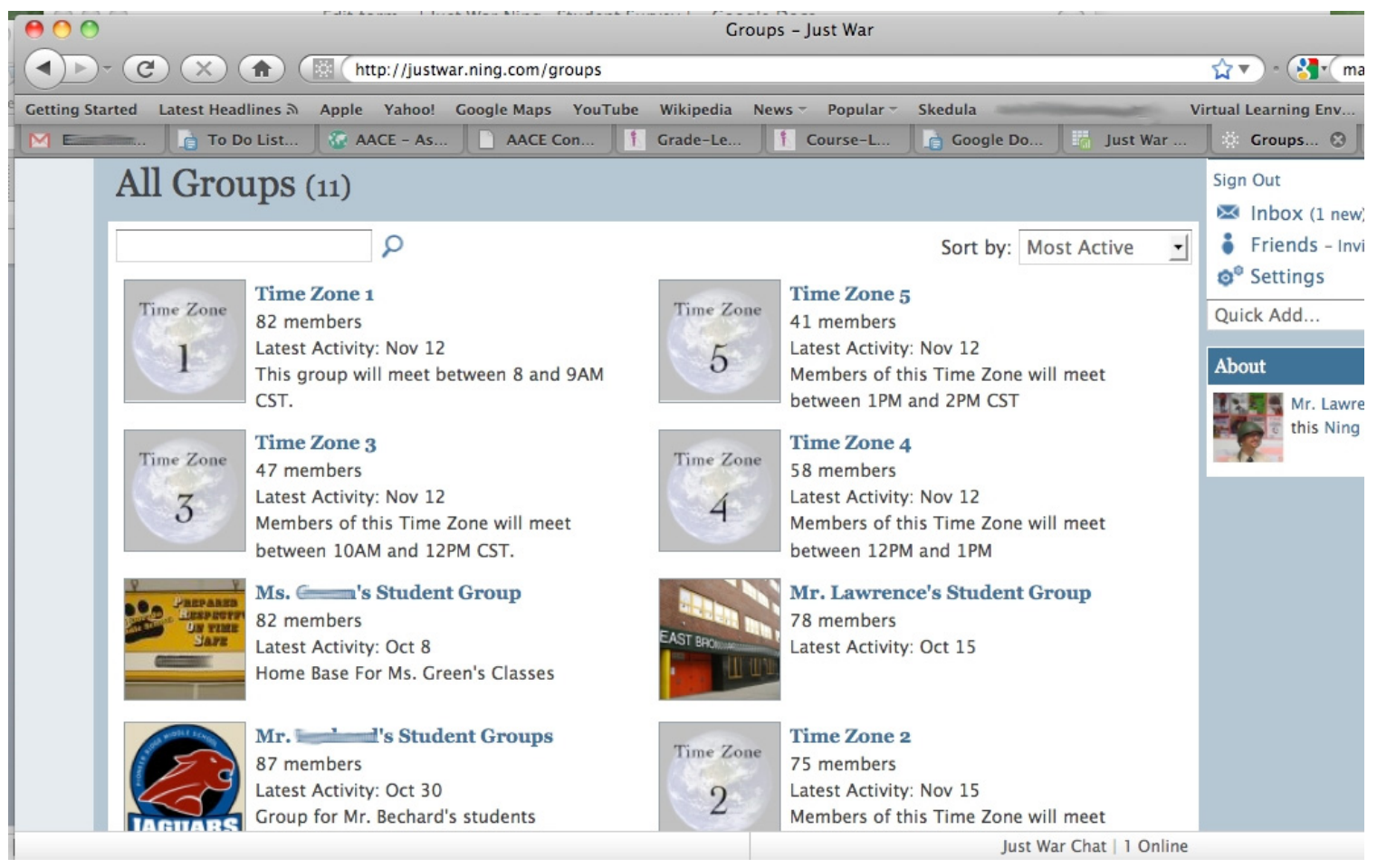

Screenshot 2. Group pages

Second, based on when each $\mathrm{f} 2 \mathrm{f}$ class of students was meeting in real time in the various schools,groups labeled "Time Zones" were set up on the site to break up the three hundred students into four interschool, synchronous, online discussion groups. For initial discussions, the f2f groups were as small as ten to fifteen students, while they were slightly larger in subsequent discussions as the students grew more comfortable with the model. While we realize that smaller groups are better, since we were novices at conducting interschool online discussions, this enabled us to have at least two or three teachers online at any one time to monitor and facilitate the discussion, particularly since each f2 $\mathrm{f}$ class of students also needed monitoring! Next year we will create several online "classes" in each Time Period so as to have two to four discussions occurring simultaneously with a teacher monitoring both an online "class" and her or his f2f class. 
Table 2. Online \& f2f instruction

\begin{tabular}{ll}
\hline Student Grouping \\
\hline Year 1 & f2f \\
Prep & - Whole class (20-30 students per class) \\
& - Small groups (5-7 students, 5 groups per \\
& class) \\
& - Preparation for live discussions done \\
& primarily f2f \\
Live & - Small groups (5-7 students, 5 groups per \\
& class) \\
& $\circ \quad$ Posting initial responses to prompts as a \\
& group. \\
& - Whole group \\
& $\circ \quad$ Teacher addresses whole class as they \\
& have discussion
\end{tabular}

Year 2

\begin{tabular}{|c|c|}
\hline \multirow{3}{*}{ Prep } & f2f \\
\hline & $\begin{array}{l}\text { - Whole class (20-30 students per class) } \\
\text { - Small groups (5-7 students, } 5 \text { groups per } \\
\text { class) }\end{array}$ \\
\hline & $\begin{array}{l}\text { - Preparation for live discussions done } \\
\text { primarily f2f }\end{array}$ \\
\hline \multirow[t]{5}{*}{ Live } & $\begin{array}{l}\text { - Small groups (5-7 students, } 5 \text { groups per } \\
\text { class) }\end{array}$ \\
\hline & $\begin{array}{l}0 \text { Posting initial responses to prompts as a } \\
\text { group. }\end{array}$ \\
\hline & $\begin{array}{l}\text { Students discuss postings in } \mathrm{f} 2 \mathrm{f} \text { group as } \\
\text { online discussion proceeds* }\end{array}$ \\
\hline & - Whole group \\
\hline & $\begin{array}{l}\text { Teacher addresses whole class as they have } \\
\text { discussion }\end{array}$ \\
\hline
\end{tabular}

\section{Online}

- Each teacher has their own group/ classroom space onNing to hold discussions.

- Space used to familiarize students with Ning's functions

- Space used at teacher's discretion for prepping live discussions.

- 5 Time Zones

- 2-4 classes meet (40-100 students)

- Initial Discussions- subdivided into smaller groups of 10-15 students

- Later discussions- all students responding to same discussion thread

- Group(s) monitored by all teachers online in given Time Zone

\section{Ning}

- $\quad$ Each teacher has their own space on Ning to hold discussions.

- Used to familiarize students with Ning's functions and to prepare for

live discussions.

\section{- 5 Time Zones}

- 2-4 classes meet (40-100 students)

- Subdivided into smaller online "Classrooms" with one teacher monitoring thelive discussion*

- Each "Classroom" has approximately 5 groups of 4-7 students from various $\mathrm{f} 2 \mathrm{f}$ classrooms*

- Whole group- The International Delegate addressesentire Just War Ning community after each day of live discussion

We addressed numerous pedagogical support issues, but one unique both to OSDs and to the cultivation of student voice proved particularly pertinent. While conducting asynchronous discussions would have logistically simplified our work, cultivation of students' "online voice" depended upon "the belief that one can reach other people: an audience" (Levine, 2008). We built in "an audience" in two ways. First, the university professor among us served as an "international delegate." He was responsible for: summarizing all the students' comments; posting a memo to the students on the Just War Ning; and, "sitting in" on all the discussions. Second, during the OSDs students were required to comment on the postings of their peers from other schools and to receive comments in return so that each student realized they were presenting to an online audience. The importance of an audience to the development of students' online voice became apparent to us in several ways. By the third discussion, for example, students were excited to learn what the international delegate had to say about their discussion threads, which illustrated they realized that they were "speaking" to someone other than the other 
students. Regarding the interschool audience, initially most students were not pleased when students from other schools disagreed with them. After several discussions though they came to enjoy disagreeing with their peers and seemed to view the discussions as a friendly, respectful and thoughtful competition of ideas. The online discussions' effectiveness was borne out by the before and after list of reasons that justified a nation going to war, a list whose sophistication surprised us.

\subsection{A Sample of the Student's Thinking}

While what we undertook might seem daunting, the richness of the students' thinking and their eagerness to participate in what became a monthly discussion demonstrated why we wholeheartedly endorse interschool online discussions about substantive policy issues grounded in history. While the reasons that the students initially identified roughly remained the same, several features distinguished their first or formative list in Table 3 from the last or summative one in Table 4. First, by the time they composed the last list, students unknowingly had ranked the reasons. Second, each reason was more fully described. Third, they supported their reasoning with historical examples, on occasions with examples addressed in their respective courses but not as a formal part of the online discussion. Finally, during their last online discussion when they were presented with a description of what was occurring in Bahrain and Yemen at the time, they were well versed enough in the reasons that each one became a working hypothesis that students "tested" as they applied their thinking to the two nations.

Table 3. Formative lists of reasons nations go to war

Formative lists of reasons

1. Self defense: another nation(s) attacks the U.S. (Examples: another nation bombs U.S. or attacks U.S. ships)

2. "Preemptive" self-defense: if another nation seems prepared to attack U.S., then U.S. is justified attacking first. (Examples: stop another nation from developing weapons of mass destruction or ensure national self-respect, i.e. if U.S. doesn't act, other nations are likely to lose respect and believe U.S. won't act if a future crisis arose.)

3. Help allies/friends: even if U.S. is not attacked, U.S. can go to war to protect a friend. (Example: a nation attacks an ally.)

4. Protect what we believe in: some democratic principles are so important that U.S. must make sure that they are honored. (Examples: if another nation keeps a people from becoming free or is killing people because of their religious beliefs.)

5. Protect U.S. economic interests: economic health of U.S. depends upon getting goods such as oil and food. (Example: a nation is keeping oil from reaching U.S.)

6. Protect innocent \& punish the inhumane treatment of other people. (Example: a nation is killing a large number of its own people.)

7. A nation is not willing and/or able to stop something that harms U.S. (Example: Mexico's inability to stop flow of drugs into U.S., which are killing U.S. citizens.)

8. Stop war between other nations. (Example: if a war threatens U.S. interests, such as the shipping of important goods like oil or food.)

9. Fight threats to U.S. that are not caused by a nation. (Example: terrorism)

10. Demonstrate strength of U.S.: if other nations realize your strength, then they are not likely to take advantage of you. It is okay to fight simply to show that you can and will. 
Table 4. Summative list of reasons why nations go to war

\section{Categories}

Consensus reasons

Self-defense: Another nation "attacks" the U.S. Students disagreed on how serious the "attack" had to be before going to war.

Protect allies: Two ideas at work. First, nations should help their friends because that is what friends do, but also "because one day we might need our allies to help us." Second, typically allies formally have agreed to help each other, but one group cautioned, "if you help your allies you going to have more problems and more enemies."

Inhumane treatment: Discussion focused on seriousness and amount of inhumane treatment. For example, "America should not go to war if innocent people are killed because innocent people are killed everyday. Unless you mean if millions of innocent people are killed like in the Holocaust." A class discussed how to respond if a nation was starving large numbers of children.

\section{Majority/near majority reasons}

Protect vital U.S. economic interests: While most agreed with this idea, they did not agree on which resources to protect. Some groups said if a nation cut off supplies to U.S. or caused U.S. to lose money, then war was justified. The "health of U.S. depends upon getting goods such as oil and food." Othersdisagreed. "We think fighting for economic reasons would cause many unneeded, painful deaths [and] there would be a more mature way of looking at this, because fighting for just money seems quite childish to us."

Preemptive self-defense: Several groups strongly opposed this reason: "We don't think you should go to war because you think another nation might attack you. You should be ready to go to war, but don't jump to conclusions and start a war." A group responded: "What if you know that they are going to attack? What are you going to do, wait from them to do it first? Or show them you are in charge?" Some said if another nation was unwilling/unable to stop a violent problem, such as a drug war or terrorism, from spilling into U.S. then U.S. should send its military into that nation. Others said that if a nation was getting too strong and aggressive, then U.S. should use the military to stop that nation: "I think all countries should be equally powerful, if one gets powerful, than we have to be in a war. If we get too powerful than it is right for another country to step up and say 'We're all in our place, you should be in yours too.'"

Protect what we believe in: Most agreed that we should fight for what we believe in but thought, "it is a pretty broad statement." While many agreed that we should support those fighting for freedom, they wondered if this meant going to war.

\section{Strong support, but not majority}

Acquire land: Many groups thought U.S. future depended upon getting access to resources. While similar to "protect economic resources," these groups thought there were situations where a nation might have to act aggressively, particularly if a lot of other nations were seizing land and/or resources.

Make peace: Some groups thought that at times a nation should use its military to prevent or stop violence. Conducting a "small" war was necessary to prevent a larger war or the deaths of more people. One group stated "If we want peace we shouldn't go to war at all. We should make some type of treaty or something else to compromise with the other country."

\subsection{Lessons Learned about Facilitating Online Discussions or Lingering Support Concerns}

While we learned a lot about ensuring adequate managerial and technical support, not surprisingly, the most vital lesson we learned was the importance of grounding online instruction in sound pedagogy since the technology notwithstanding, all we did was engage a lot of students in a discussion. Having grounded the discussions in our respective curricula, worked out the logistical details associated with an interschool project, and gained familiarity and comfort with the Ning site, we now need to improve the discussion component of our endeavor since students will not necessarily engage in deep, rich discussions without instructional support (Webb, 2009).

1) Important to create multi-stage online discussions: In hindsight, rather than having a fairly free flowing $30-40$ minute discussion, we need to break each discussion into distinct stages that focus on a specific question. When facilitating the online discussions we need to help students summarize their responses and to provide a transition 
to the next stage of the discussion. Finally, we need to scaffold the questions, and therefore the discussion, in a way to lead students to the desired outcome and to bring closure to the discussion.

2) Purposefully manage the time of the discussion: While seemingly obvious, by trying to monitor both the students' online and $\mathrm{f} 2 \mathrm{f}$ behavior and the substance of their comments, time eluded us. As often happens with f2f discussions, there was not enough time to provide closure to a discussion. Harking back to our first point, for future discussions we plan to publish a timetable for each class period's online discussion and to indicate what students need to accomplish at each stage of the discussion.

3) Require each group of students at the end of the online discussion to post how they would respond: If we want students not only to thoughtfully consider and apply their list of reasons, then we need to more purposefully capitalize on what they learned during each online discussion. While we conducted $\mathrm{f} 2 \mathrm{f}$ debriefings after each discussion, we failed to have students summarize their thinking. This has led us to a two-fold outcome for the online discussions. First, in f2f settings prior to the debriefing students should answer the overarching question or two that was posed at the beginning of eachonline discussion and to clearly state their thinking about and position on each hypothetical situation, such as whether military action was justified. Second, students need to record their thinking and post on their class home page.

4) Being online doesn't necessitate having to stay online the whole time: There was a tendency to feel compelled to remain online the entire time. If students need to summarize and formalize their thinking, for example, then a hybrid approach to the online discussion becomes appropriate. Toward the end of the discussion students should work offline for several minutes in their class groups to present a formal statement of their thinking and then to post their statement online for one last round of comments.

5) More purposefully scaffold the series of online discussions: Ironically, while during both the f2f preparation for and debriefing of the online discussions we were conscious of drawing upon the students' list of reasons and prior situations, rarely did the questions posed during the online discussions cause students to draw upon prior learning. Obviously, if we treated each discussion as discrete from the other ones, then students were likely to do the same. We realize now, for example the need to build in questions that cause students to compare each new hypothetical situation with prior ones, such as asking students to compare the economic reason(s) for the War of 1812 and the Spanish-American War.

\section{Conclusion}

If bringing 300 early adolescents together for any reason seems like a half-baked idea, then letting them loose on a SNS certainly must be a recipe for disaster! Instead, engaging students in a thoughtful and thought provoking series of discussions about a serious public policy matter in what they typically think of as a social setting resulted in cognitive treats, which would delight any social studies teacher. We realized the power of our undertaking when a $7^{\text {th }}$ grade group in response to a group of $8^{\text {th }}$ graders advocating for preemptive self-defense wrote: "We don't want people to die, but we don't want to lose our oil." Clearly, they were grappling with war's complexity. If as Levine (2008) notes, "democracy requires broad and diverse cultural creativity" and the "new digital media...offer opportunities for individuals and voluntary groups to create their own cultural products and to use a public voice" about matters of personal interest and social importance, then we think our efforts represent a starting point in fostering a disposition and the skills among our students "to make products with public purposes" and to exercise their online voice (Levine, p. 129).

\section{References}

An, H., Kim, S., \& Kim, B. (2008). Teacher perspectives on online collaborative learning: Factors perceived as facilitating and impeding successful online group work. Contemporary Issues in Technology and Teacher Education, 8(1), 65-83. Retrieved from http://www.citejournal.org/

Ashton, S., Roberts, T., \& Teles, L. (1999). Investigating the role of the instructor in collaborative online environments. Poster presented at the computer support for collaborative learning (CSCL) 1999 conference, Palo Alto, Stanford University, CA.

Asterhan, C. S. C., \& Schwarz, B. B. (2010). Online moderation of synchronous e-argumentation.International Journal of Computer-Supported Collaborative Learning, 5, 259-282. http://doi.dx.org/10.1007/s11412-010-9088-2

Bowler, M. (2009). Learning to 'chat' in a virtual learning environment: Using online synchronous discussion to conduct a first year undergraduate tutorial. Paper presented at the British Educational Research Association Annual Conference, University of Manchester, 2-5 September 2009. 
Branon, R. F., \& Essex, C. (2001). Synchronous and asynchronous communication tools in distance education: A survey of instructors. Tech Trends, 1(45), 35.

Bull, G., Thompson, A., Searson, M., Garofalo, J., Park, J., Young, C., \& Lee, J (2008). Connecting informal and formal learning: Experiences in the age of participatory media. Contemporary Issues in Technology and Teacher Education, 8(2). Retrieved from http://www.citejournal.org/

Chen, C., \& Bradshaw, A. C. (2007). The effect of web-based question prompts on scaffolding knowledge integration and ill-structured problem solving. Journal of Research on Technology in Education, 39, 359-375.

Chen, N. S., Ko, H. C., Kinshuk \& Lin, T. (2005). A model for synchronous learning using the Internet.Innovations in Education and Teaching International, 42(2), 181-194. http://doi.dx.org/10.1080/14703290500062599

Greenhow, C., Robelia, B., \& Hughes, J. E. (2009). Learning, teaching, and scholarship in a digital age: Web 2.0 and classroom research - what path should we take now? Educational Researcher, 38, 246-258. http://doi.dx.org/10.3102/0013189X09336671

Lankes, R. D. (2008). Trusting the Internet: New approaches to credibility tools. In M.J. Metzger \& A.J. Flanagin (Eds.), Digital media, youth, and credibility (pp. 101-122). Cambridge, MA: The John D. and Catherine T. MacArthur Foundation Series on Digital Media and Learning.

Lenhart, A., Ling, R., Campbell, S, \& Purcell, K. (2010). Teens and Mobile Phones. Pew Internet \& American Life Project. Retrieved from http://pewinternet.org/Reports/2010/Teens-and-Mobile-Phones.aspx

Levine, P. (2008). A Public voice for youth: The audience problem in digital media and civic education. In W.L. Bennett (Eds.), Civic life online: Learning how digital media can engage youth (pp.119-138). Cambridge, MA: The MIT Press.

Lind, K. (2004). Human support in CSCL: What, for whom, and by whom? In Kirschner, J-W.\& Martens, P.A.(Eds.), What We Know about CSCL in Higher Education, (pp. 167-198).

National Council for the Social Studies (1994). Expectations of Excellence: Curriculum Standards for the Social Studies, NCSS Bulletin 89. Washington, DC: NCSS.

Rheingold, H. (2008). Using participatory media and public voice to encourage civic engagement. In Bennett, W.L. (Ed.), Civic Life Online: Learning How Digital Media Can Engage Youth (pp. 97-118). Cambridge, MA: The MIT Press.

Shi, S., Bonk, C., Tan, S., \& Mishra, P. (2008). Getting in sync with synchronous: The dynamics of synchronous facilitation in online discussions. International Journal of Instructional Technology and Distance Learning, 5(5), 3-28.

Wang, C. (2005). Questioning skills facilitate online synchronous discussions. Journal of Computer Assisted Learning, 21, 303-313. http://doi.dx.org/10.1111/j.1365-2729.2005.00138.x

Webb, N. M. (2009). The teacher's role in promoting collaborative dialogue in the classroom. British Journal of Educational Psychology, 79, 1-28. http://doi.dx.org/10.1348/000709908X380772 